\title{
Carbon-Type Analysis and Comparison of Original and Reblended FACE Diesel Fuels (FACE 2, FACE 4, and FACE 7)
}

\author{
JT Bays \\ DL King \\ MJ O'Hagan
}

October 2012

Pacific Northwest

NATIONAL LABORATORY

Proudly Operated by Battelle Since 1965 


\title{
DISCLAIMER
}

This report was prepared as an account of work sponsored by an agency of the United States Government. Neither the United States Government nor any agency thereof, nor Battelle Memorial Institute, nor any of their employees, makes any warranty, express or implied, or assumes any legal liability or responsibility for the accuracy, completeness, or usefulness of any information, apparatus, product, or process disclosed, or represents that its use would not infringe privately owned rights. Reference herein to any specific commercial product, process, or service by trade name, trademark, manufacturer, or otherwise does not necessarily constitute or imply its endorsement, recommendation, or favoring by the United States Government or any agency thereof, or Battelle Memorial Institute. The views and opinions of authors expressed herein do not necessarily state or reflect those of the United States Government or any agency thereof.

\author{
PACIFIC NORTHWEST NATIONAL LABORATORY \\ operated by \\ BATTELLE \\ for the \\ UNITED STATES DEPARTMENT OF ENERGY \\ under Contract DE-AC05-76RL01830
}

Printed in the United States of America
Available to DOE and DOE contractors from the Office of Scientific and Technical Information,
P.O. Box 62, Oak Ridge, TN 37831-0062;
ph: (865) 576-8401
fax: $(865) 576-5728$
email: reports@adonis.osti.gov
Available to the public from the National Technical Information Service 5301 Shawnee Rd., Alexandria, VA 22312 ph: (800) 553-NTIS (6847)
email: orders@ntis.gov <http://www.ntis.gov/about/form.aspx>
Online ordering: http://www.ntis.gov

This document was printed on recycled paper. 


\title{
Carbon-Type Analysis and Comparison of Original and Reblended FACE Diesel Fuels (FACE 2, FACE 4, and FACE 7)
}

\author{
JT Bays \\ DL King \\ MJ O’Hagan
}

October 2012

Prepared for

the U.S. Department of Energy

under Contract DE-AC05-76RL01830

Pacific Northwest National Laboratory

Richland, Washington 99352 



\section{Summary}

This report summarizes the carbon-type analysis from ${ }^{1} \mathrm{H}$ and ${ }^{13} \mathrm{C}\left\{{ }^{1} \mathrm{H}\right\}$ nuclear magnetic resonance spectroscopy (NMR) of Fuels for Advanced Combustion Engines (FACE) diesel blends, FD-2B, FD-4B, and FD-7B, and makes comparison of the new blends with the original FACE diesel blends, FD-2A, FD-4A, and FD-7A. Overall, the new FACE fuel blends are fairly consistent with the original FACE fuel blends, but there are observable differences. Generally, FD-2A and FD-2B are more similar than the A and B blends of FD-4 and FD-7. The overall aromatic carbon content is higher for the new FACE blends, with the new FACE blends having decreased monoaromatic content and increased di- and tri-

cycloaromatic content, as well as a slightly higher overall aromatic content, than the original FACE blends. The aromatic components of the new FACE blends generally have a higher alkyl substitution with longer alkyl substituents. The naphthenic and paraffinic contents remained relatively consistent between each of the old and new blends. Based on established correlations of aliphatic methyl and methylene carbon ratios with cetane values, cetane numbers for FD-2A and -2B, and FD-7A and -7B are expected to be consistent, while the cetane number for FD-4B is predicted to be higher than FD-4A. In addition to providing important comparative compositional information on reformulated FACE diesel blends, this report also provides important information about the capabilities of the team at Pacific Northwest National Laboratory in the use of NMR spectroscopy for the detailed characterization and comparison of fuels and fuel blends. 



\section{Acknowledgments}

The authors gratefully acknowledge the U.S. Department of Energy, Energy Efficiency and Renewable Energy, Office of Vehicle Technology, for their programmatic support. We sincerely appreciate the valuable interactions we have had with members of the Coordinating Research Council (CRC) Fuels for Advanced Combustion (FACE) Working Group and other Advanced Vehicle Fuels and Lubricants Committees. We also thank Drs. John C. Linehan and Wendy J. Shaw for their helpful discussions and advice. 



\section{Acronyms and Abbreviations}

COSY

CRC

FACE

HMBC

HSQC

INADEQUATE

NMR

NOE

TOCSY correlation spectroscopy

Coordinating Research Council

Fuels for Advanced Combustion Engines

Heteronuclear Multiple Bond Correlation

Heteronuclear Single Quantum Coherence

Incredible Natural-Abundance DoublE-QUAntum Transfer Experiment

nuclear magnetic resonance

nuclear Overhauser enhancement

total correlation spectroscopy 



\section{Contents}

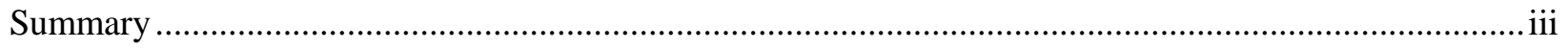

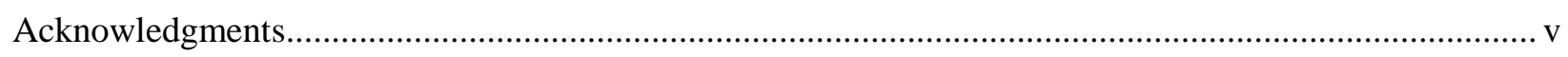

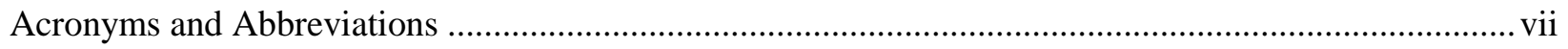

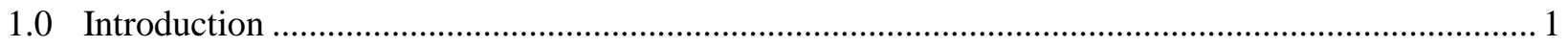

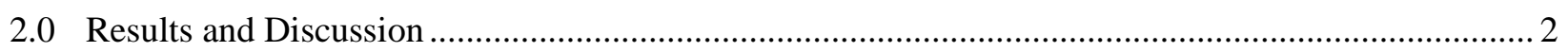

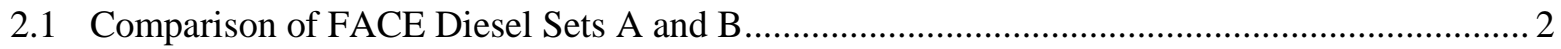

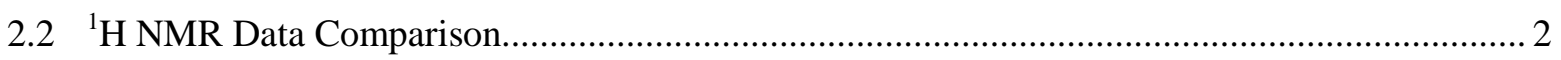

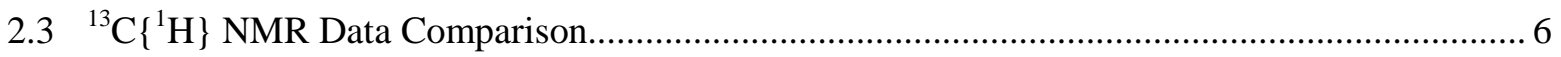

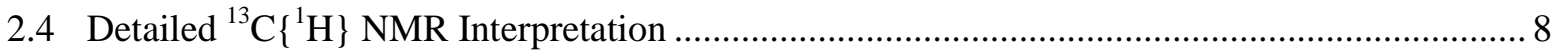

2.5 Comparison of ${ }^{1} \mathrm{H}$ and ${ }^{13} \mathrm{C}\left\{{ }^{1} \mathrm{H}\right\}$ NMR Results for FACE “B” Diesel Fuels ............................. 11

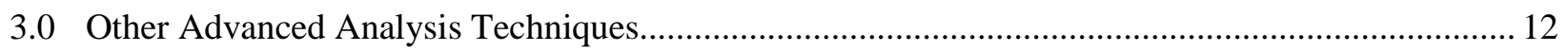

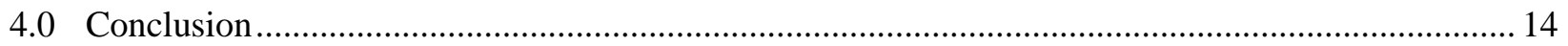

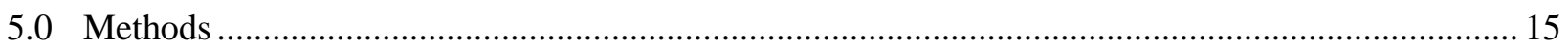

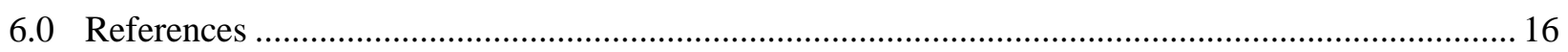




\section{Figures}

1 Normalized Carbon Type Distribution of Original and Reblended FACE Diesel Fuels FD-2, FD-4, and FD-7

2 Nomenclature Scheme Describing Distance from an Aromatic Ring, or from the End of an

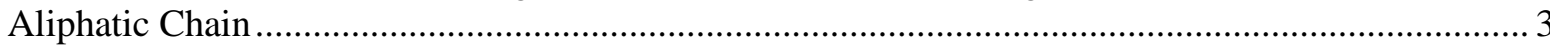

3 Normalized Carbon Type Distribution of Reblended FACE Diesel Fuels FD-2B, FD-4B, and FD-7B

4 Single-bond, Proton-Carbon Correlation (HSQC) NMR Spectra of Fuels: (a) FACE 2B

(FD-2B), (b) FACE 4B (FD-4B), (c) FACE 7B (FD-7B), (d) Shale oil-derived Diesel 1, and

(e) Oil sands-derived diesel

\section{Tables}

1 FACE Diesel Target Parameters (Alnajjar et al. 2010) .................................................................. 1

2 Comparison of Normalized ${ }^{13} \mathrm{C}\left\{{ }^{1} \mathrm{H}\right\}$ Percent Composition Between Original and Reblended

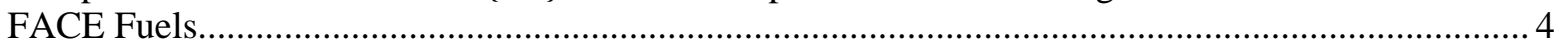

$3 \quad{ }^{1} \mathrm{H}$ NMR Comparison of Original and Reblended FACE Fuels, Normalized by Hydrogen

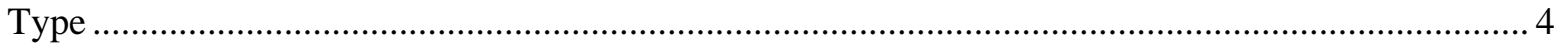

$4 \quad{ }^{1}$ H NMR Comparison of Original and Reblended FACE Fuels, Percent Normalized by Carbon Type

$5 \quad{ }^{1}$ H NMR Aromatic Region, Breakdown of Fused, Protonated Aromatic Rings, Percent Results Normalized by Carbon Type ............................................................................................ 5

6 Detailed Chemical Shift Regions for Normalized ${ }^{13} \mathrm{C}\left\{{ }^{1} \mathrm{H}\right\}$ Percent Composition of Reblended FACE Fuels

7 Summary of New FACE Diesel Chemical Structure Characteristics from ${ }^{13} \mathrm{C}\left\{{ }^{1} \mathrm{H}\right\} \mathrm{NMR}$

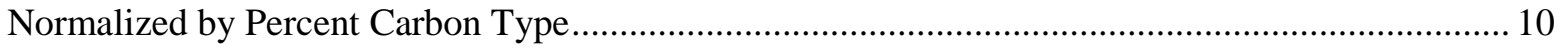

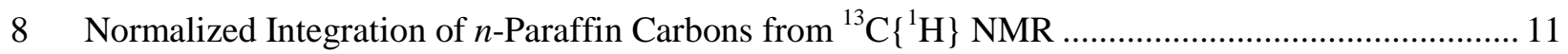

$9 \quad{ }^{1} \mathrm{H}$ and ${ }^{13} \mathrm{C}\left\{{ }^{1} \mathrm{H}\right\}$ NMR Comparison of Aromatic Characteristics, Results Normalized by Carbon Type

$10{ }^{1} \mathrm{H}$ and ${ }^{13} \mathrm{C}\left\{{ }^{1} \mathrm{H}\right\}$ NMR Comparison of Aliphatic Carbons, Results Normalized by Carbon Type 


\subsection{Introduction}

This report summarizes the carbon-type analysis from ${ }^{1} \mathrm{H}$ and ${ }^{13} \mathrm{C}\left\{{ }^{1} \mathrm{H}\right\}$ nuclear magnetic resonance spectroscopy (NMR) ${ }^{(a)}$ of Fuels for Advanced Combustion Engines (FACE) diesel blends, FD-2B, FD-4B, and FD-7B, and makes comparison of these new blends with the original FACE diesel blends, FD-2A, FD-4A, and FD-7A. The physically available quantities of these fuels (FD-2A, -4A, and -7A, reported on the Coordinating Research Council (CRC) website (Alnajjar et al. 2010), were depleted. Additionally, one or more of the original refinery streams used to blend each fuel were sufficiently changed over time that the fuels needed to be reformulated and reanalyzed. We provide a comparison of the reblended fuels with the original fuel blends, as well as highlight some of the unique information provided by the NMR analyses.

In preparing the reblended diesel fuels (version B fuels), attempts were made to closely match the original FACE diesel blends (version A fuels). Targeted parameters included cetane number, aromatic content, and volatility $\left(\mathrm{T}_{90}\right)$, according to Table 1 (note there are nine FACE diesel fuels in total, comprising high and low value combinations for each of the three parameters, plus a center point). The targeted aromatic compositions by volume are $20 \%$ for the low value and $45 \%$ for the high value (Alnajjar et al. 2010). The carbon-type analysis presented here does not lend itself to a direct comparison with the percent-by-volume targets presented in Table 1, but can provide a relative measure of aromatic content; that is, we should observe that the percent-aromatic-carbons detected using the NMR methods for FD-2B should be about half of that for FD-4B and FD-7B. The carbon-type analysis identifies the number of aromatic carbons, but does not directly convey the mole percent of aromatic molecules. The structure of an average aromatic molecule can be derived, and from that an average structural density, which could then be related to the percent-by-volume, but the inherent uncertainty of these estimates is such that we do not make them here.

Table 1. FACE Diesel Target Parameters (Alnajjar et al. 2010)

\begin{tabular}{cccc}
\hline Fuel & Cetane Number & Aromatic Content & $\mathbf{T}_{\mathbf{9 0}}$ \\
\hline FD-2 & Low (30) & Low $(20 \%)$ & High $\left(340^{\circ} \mathrm{C}\right)$ \\
FD-4 & Low (30) & High $(45 \%)$ & High $\left(340^{\circ} \mathrm{C}\right)$ \\
FD-7 & High (55) & High $(45 \%)$ & Low $\left(270^{\circ} \mathrm{C}\right)$ \\
\hline
\end{tabular}

(a) To avoid confusion in this document, ${ }^{13} \mathrm{C}\left\{{ }^{1} \mathrm{H}\right\}$ will be the symbol used to represent ${ }^{\text {" }}{ }^{13} \mathrm{C}$ NMR spectroscopy." ${ }^{13} \mathrm{C}\left\{{ }^{1} \mathrm{H}\right\}$ is the appropriate symbol for the proton-decoupled ${ }^{13} \mathrm{C}$ NMR experiment performed in this study. By running the experiment as ${ }^{1} \mathrm{H}$ decoupled, we improve the ${ }^{13} \mathrm{C}$ NMR signal-to-noise ratio by preventing each carbon signal from being split by attached protons, as well as reduce the signal complexity that would result from that splitting. The ${ }^{1} \mathrm{H}$-coupled signals of a ${ }^{13} \mathrm{C}$ NMR would be largely unintelligible for a complex mixture, making interpretation of the ${ }^{13} \mathrm{C}$ spectrum either much more difficult or impossible. 


\subsection{Results and Discussion}

\subsection{Comparison of FACE Diesel Sets A and B}

In order to provide the best comparison between the previous FACE diesel blends (labeled as A) and the new FACE diesel blends (labeled as B), the data are provided in the same format as was previously presented in the 2010 CRC Report (Alnajjar et al. 2010). Figure 1 shows a graphic representation of the quantitative ${ }^{13} \mathrm{C}\left\{{ }^{1} \mathrm{H}\right\}$ NMR results for FACE Diesel Sets A and B using the same spectral ranges as the original report. Tables 2 and 3 provide a side-by-side comparison of normalized quantitative ${ }^{13} \mathrm{C}\left\{{ }^{1} \mathrm{H}\right\}$ and ${ }^{1} \mathrm{H}$ NMR data, respectively. The ${ }^{1} \mathrm{H}$ NMR spectra of fuels are relatively uncomplicated and easy to obtain, but contain a wealth of information. To show the compatibility of ${ }^{1} \mathrm{H}$ and ${ }^{13} \mathrm{C}\left\{{ }^{1} \mathrm{H}\right\}$ NMR data and to allow a direct quantitative comparison of similar structural information, we have related each hydrogen resonance to the attached carbon type, as shown in Table 4. ${ }^{\text {(a) }}$ Figure 2 provides a description of carbon positions as annotated in this document with respect to either distance from an aromatic ring or position within an aliphatic chain. Samples of the original diesel blends were not re-analyzed for this study, but data were taken from the 2010 CRC Report (Alnajjar et al. 2010).

\section{2 ${ }^{1} \mathrm{H}$ NMR Data Comparison}

The normalized ${ }^{1} \mathrm{H}$ NMR data shown in Table 3 show that the variations between the FACE A and FACE B fuel sets are relatively minor. FD-2A and FD-2B appear to be the most similar in makeup, with more pronounced differences arising in FD-4 and FD-7.

Examination of the ${ }^{1} \mathrm{H}$ NMR results normalized to carbon type, shown in Table 4, reveal that the new aromatic blend stream(s) contain(s) a greater fraction of fused-ring, polyaromatic compounds, and a higher overall aromatic composition than the original FACE blends. By breaking down the protonated aromatic region of the ${ }^{1} \mathrm{H}$ NMR for the FACE B blends, we can more closely examine the makeup of the polyaromatic components. The ability to readily assess fused-ring aromatic content is an advantage of ${ }^{1} \mathrm{H}$ NMR that is more difficult to obtain from ${ }^{13} \mathrm{C}\left\{{ }^{1} \mathrm{H}\right\}$ NMR spectra. Presented in Table 5 are generally accepted ${ }^{1} \mathrm{H}$ NMR regions associated with fused ring di- and triaromatics; that is, substituted naphthalenes, and anthracenes or phenylanes/phenanthrenes, respectively (Algelt and Boduszynski 1994). From Table 5, we can see that the polyaromatic components presented in Tables 3 and 4 are predominantly made up of diaromatic species (naphthalenes), with an additional fraction of triaromatics, comprising between about $10-15 \%$ of the diaromatics. Fused-ring structures greater than three, which have resonances between 8.3 and 10.7 ppm, were not observed.

(a) For example, a methyl group $\left(-\mathrm{CH}_{3}\right)$ contributes 3 protons but only 1 carbon; thus, the integrated value from the $-\mathrm{CH}_{3}$ region of the ${ }^{1} \mathrm{H}$ NMR spectrum representing methyl groups was divided by 3 , and so forth for each integration zone, and then normalized to reflect the number of unique carbon environments. This process does not account for carbons without protons (i.e., substituted aromatic carbons, bridgehead carbons, or quaternary carbons), so the tabulated values will be higher than the actual values, depending upon the number of carbons without protons, but since these are usually small, will provide results that trend correctly. 


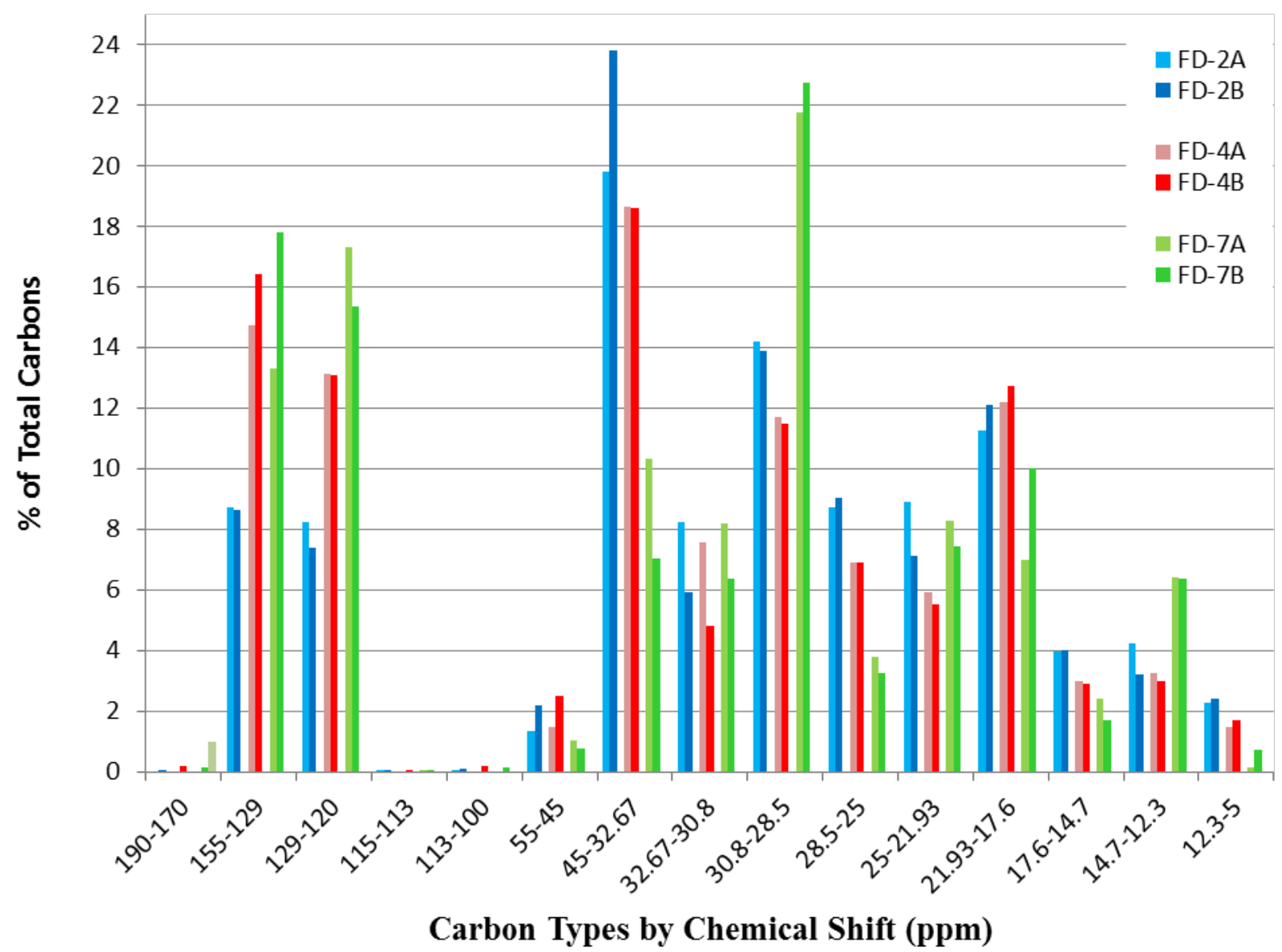

Figure 1. Normalized Carbon Type Distribution of Original and Reblended FACE Diesel Fuels FD-2, FD-4, and FD-7. Values were obtained by integrating each ${ }^{13} \mathrm{C}\left\{{ }^{1} \mathrm{H}\right\}$ NMR chemical shift region.

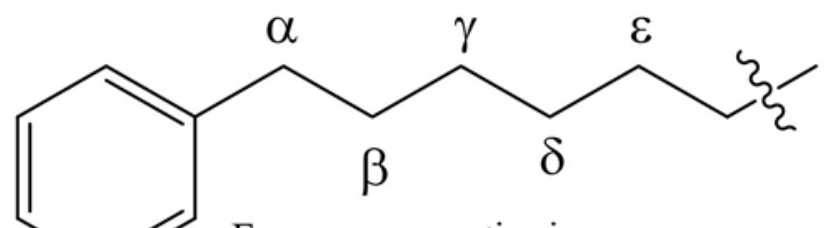

From an aromatic ring

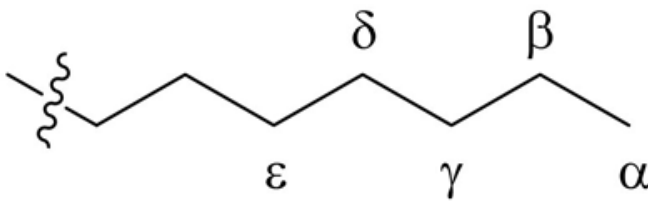

From the end of an aliphatic chain

Figure 2. Nomenclature Scheme Describing Distance from an Aromatic Ring, or from the End of an Aliphatic Chain 
Table 2. Comparison of Normalized ${ }^{13} \mathrm{C}\left\{{ }^{1} \mathrm{H}\right\}$ Percent Composition Between Original and Reblended FACE Fuels

\begin{tabular}{|c|c|c|c|c|c|c|c|c|}
\hline \multirow[b]{2}{*}{ Label } & \multirow{2}{*}{$\begin{array}{l}\text { Chemical } \\
\text { Shift (ppm) }\end{array}$} & \multirow[b]{2}{*}{ Structure Definition } & \multicolumn{6}{|c|}{$\% \mathrm{C}$} \\
\hline & & & FD-2A ${ }^{(a)}$ & FD-2B & FD-4A ${ }^{(a)}$ & FD-4B & FD-7A $^{(a)}$ & FD-7B \\
\hline CA1 & $190-170$ & $\begin{array}{l}\text { Oxygenated carbon (ketone, } \\
\text { carboxylate) }\end{array}$ & 0 & 0.08 & 0 & 0.18 & 0 & 0.15 \\
\hline CA2 & $155-129$ & Quaternary aromatic & 8.72 & 8.65 & 14.73 & 16.42 & 13.33 & 17.78 \\
\hline CA3 & $129-120$ & Aromatic C-H & 8.26 & 7.41 & 13.15 & 13.09 & 17.32 & 15.36 \\
\hline CA4 & 115-113 & Olefinic $\mathrm{CH}$ & 0.07 & 0 & 0 & 0.02 & 0.02 & 0.07 \\
\hline CA5 & $113-100$ & Olefinic $\mathrm{CH}_{2}$ & 0.02 & 0.08 & 0 & 0.19 & 0 & 0.16 \\
\hline CP1 & $55-45$ & Paraffinic $\mathrm{CH}$ & 1.34 & 2.18 & 1.47 & 2.49 & 1.06 & 0.76 \\
\hline СР2 & $45-32.67$ & Paraffinic $\mathrm{CH}^{*} \mathrm{CH}_{2}$ & 19.79 & 23.80 & 18.63 & 18.59 & 10.31 & 7.06 \\
\hline СР3 & $32.67-30.8$ & $\begin{array}{l}\text { Chain } \gamma \text { - } \mathrm{CH}_{2} \beta \text {-to-aromatic } \mathrm{CH}_{2} \text {; } \\
\text { chain } \delta \text { - } \mathrm{CH}_{2} \alpha \text {-to-aromatic } \\
\text { naphthenes }\end{array}$ & 8.25 & 5.92 & 7.56 & 4.80 & 8.18 & 6.36 \\
\hline СР4 & $30.8-28.5$ & Aromatic-attached ethyl $\mathrm{CH}_{2}$ & 14.18 & 13.90 & 11.70 & 11.47 & 21.76 & 22.71 \\
\hline CP5 & $28.5-25$ & Cycloparaffin $\mathrm{CH}_{2}$ & 8.72 & 9.03 & 6.90 & 6.91 & 3.79 & 3.26 \\
\hline CP6 & 25-21.93 & $\begin{array}{l}\text { Chain } \beta-\mathrm{CH}_{2}, \alpha \text { to aromatic or } \\
\text { isobutyl } \mathrm{CH}_{3}\end{array}$ & 8.91 & 7.15 & 5.91 & 5.51 & 8.27 & 7.46 \\
\hline CP7 & 21.93-17.6 & $\alpha$-to-ring $\mathrm{CH}_{3}$ & 11.28 & 12.13 & 12.20 & 12.73 & 7.00 & 10.04 \\
\hline СР8 & $17.6-14.7$ & Aromatic-attached ethyl $\mathrm{CH}_{3}$ & 3.99 & 4.01 & 2.98 & 2.91 & 2.41 & 1.73 \\
\hline СР9 & $14.7-12.3$ & Chain $\alpha-\mathrm{CH}_{3}$ & 4.22 & 3.20 & 3.28 & 2.98 & 6.41 & 6.39 \\
\hline CP10 & $12.3-5$ & Branched-chain $\mathrm{CH}_{3}$ & 2.27 & 2.43 & 1.49 & 1.71 & 0.13 & 0.71 \\
\hline
\end{tabular}

(a) Data for FD-2A, FD-4A, and FD-7A are taken from the original CRC Report (Alnajjar et al. 2010).

Table 3. $\quad{ }^{1} \mathrm{H}$ NMR Comparison of Original and Reblended FACE Fuels, Normalized by Hydrogen Type

\begin{tabular}{lllccccccc}
\hline & & & Chemical & \multicolumn{7}{c}{ \%H } \\
\cline { 6 - 10 } Label & Structure & Definition & Shift $(\mathbf{p p m})$ & FD-2A $^{(\mathbf{a})}$ & FD-2B & FD-4A $^{(\mathbf{a})}$ & FD-4B & FD-7A $^{(\mathbf{a})}$ & FD-7B \\
\hline HA1 & polyaromatic & $\mathrm{CH}$ & $7.4-10.7$ & 0.2 & 0.9 & 0.3 & 2.4 & 0.4 & 3.0 \\
HA2 & monoaromatic & $\mathrm{CH}$ & $7.4-6.2$ & 3.6 & 3.6 & 7.3 & 6.7 & 8.6 & 7.3 \\
HO1 & olefinic & $\mathrm{CH}$ & $5.1-6.2$ & 0 & 0 & 0 & 0 & 0 & 0 \\
HO2 & olefinic & $\mathrm{CH}_{2}$ & $4.8-5.1$ & 0 & 0 & 0 & 0 & 0 & 0 \\
HO3 & olefinic & $\mathrm{CH}_{2}$ & $4.3-4.8$ & 0 & 0 & 0 & 0 & 0 & 0 \\
HP1 & a-to-aromatic & $\mathrm{CH}_{2}$ & $2.4-4.3$ & 1.7 & 2.2 & 2.7 & 12.2 & 5.0 & 13.8 \\
HP2 & a-to-aromatic & $\mathrm{CH}_{3}$ & $2.0-2.4$ & 5.8 & 5.6 & 11.8 & 5.4 & 8.4 & 5.6 \\
\hline HP3 & aliphatic & $\mathrm{CH}_{2}$ & $1.09-2.0$ & 33.8 & 33.4 & 36.4 & 40.5 & 55.3 & 53.9 \\
HP4 & aliphatic & $\mathrm{CH}_{3}$ & $0.5-1.09$ & 55 & 54.3 & 41.5 & 32.8 & 22.3 & 16.4 \\
\hline
\end{tabular}

(a) Data for FD-2A, FD-4A, and FD-7A are taken from the original CRC Report (Alnajjar et al. 2010). 
Table 4. $\quad{ }^{1} \mathrm{H}$ NMR Comparison of Original and Reblended FACE Fuels, Percent Normalized by Carbon Type

\begin{tabular}{|c|c|c|c|c|c|c|c|c|c|}
\hline \multirow[b]{2}{*}{ Label } & \multirow[b]{2}{*}{ Structure } & \multirow[b]{2}{*}{ Definition } & \multirow{2}{*}{$\begin{array}{c}\text { Chemical } \\
\text { Shift (ppm) }\end{array}$} & \multicolumn{6}{|c|}{$\% \mathrm{C}$} \\
\hline & & & & FD-2A ${ }^{(a)}$ & FD-2B & FD-4A ${ }^{(a)}$ & FD-4B & FD-7A ${ }^{(a)}$ & FD-7B \\
\hline HA1 & polyaromatic & $\mathrm{CH}$ & $7.4-10.7$ & 0.5 & 2.1 & 0.7 & 4.9 & 0.8 & 5.8 \\
\hline HA2 & monoaromatic & $\mathrm{CH}$ & $7.4-6.2$ & 8.6 & 8.5 & 16.3 & 13.8 & 17.4 & 14.2 \\
\hline HO1 & olefinic & $\mathrm{CH}$ & $5.1-6.2$ & 0 & 0 & 0 & 0 & 0 & 0 \\
\hline $\mathrm{HO} 2$ & olefinic & $\mathrm{CH}_{2}$ & $4.8-5.1$ & 0 & 0 & 0 & 0 & 0 & 0 \\
\hline HO3 & olefinic & $\mathrm{CH}_{2}$ & $4.3-4.8$ & 0 & 0 & 0 & 0 & 0 & 0 \\
\hline HP1 & $\alpha$-to-aromatic & $\mathrm{CH}_{2}$ & $2.4-4.3$ & 2.0 & 2.6 & 3.0 & 12.7 & 5.1 & 13.4 \\
\hline HP2 & $\alpha$-to-aromatic & $\mathrm{CH}_{3}$ & $2.0-2.4$ & 4.6 & 4.5 & 8.8 & 3.8 & 5.7 & 3.6 \\
\hline HP3 & aliphatic & $\mathrm{CH}_{2}$ & $1.09-2.0$ & 40.4 & 39.5 & 40.5 & 42.0 & 56.0 & 52.3 \\
\hline HP4 & aliphatic & $\mathrm{CH}_{3}$ & $0.5-1.09$ & 43.8 & 42.8 & 30.8 & 22.7 & 15.1 & 10.6 \\
\hline
\end{tabular}

(a) Data for FD-2A, FD-4A, and FD-7A are taken from the original CRC Report (Alnajjar et al. 2010).

Table 5. $\quad{ }^{1}$ H NMR Aromatic Region, Breakdown of Fused, Protonated Aromatic Rings, Percent Results Normalized by Carbon Type

\begin{tabular}{lcccc}
\hline & \multirow{2}{*}{$\begin{array}{c}\text { Chemical Shift } \\
\mathbf{( p p m )}\end{array}$} & \multicolumn{3}{c}{ \%C } \\
\cline { 3 - 5 } Structure & $8.3-10.7$ & 0 & 0 & 0 \\
\hline Polyaromatic & $7.8-8.3$ & 0.4 & 1.3 & 1.6 \\
Triaromatic & $7.2-7.8$ & 3.1 & 8.5 & 9.5 \\
Diaromatic & $6.2-7.2$ & 7.1 & 9.1 & 9.1 \\
Monoaromatic & & & &
\end{tabular}

Also apparent from the ${ }^{1} \mathrm{H}$ NMR is a significant increase in the percent of alkyl protons bound to an aromatic ring in the FD-4 and FD-7 blends. The $\alpha$-to-aromatic methyl and methylene protons are effectively equivalent for the FD-2A and -2B diesels. Both Tables 3 and 4 show an increase in protons associated with methylene groups $\alpha$ to an aromatic ring (HP1) for all three fuel blends, and a decrease in protons attached to methyl groups $\alpha$ to an aromatic ring (HP2) for FD-4 and -7 diesel blends, implying that more of the aromatic substituent alkyl groups are longer than one carbon in the new fuels. By comparing the sum of HP1 and HP2, we can also see that on average the number of alkyl (methyl or alkyl) substitutions of each aromatic molecule has also increased for the new FD-4 and -7 blends, while remaining essentially constant for FD-2.

The aliphatic region of the ${ }^{1} \mathrm{H}$ NMR data suggests major differences between FD-4 and FD-7. The aliphatic methylene protons, HP3, remain effectively constant when comparing both fuel sets; however, the number of aliphatic methyl protons, HP4, decreased by roughly one-third in both of these fuel blends. Considering the increase in methylene/methyl ratios for both fuels, either the quantity of naphthenes (cyclic aliphatic compounds) has increased, or the overall chain length for $n$-paraffins has increased in reblending the fuels, or some combination of the two effects. 
The ratio of aliphatic methyl (CP4) to methylene (CP3) carbons may also be used as a prediction of relative cetane number. From Table 4 we obtain CP4/CP3 ratios of 1.08 for both FD-2 blends, 0.76 and 0.54 for FD-4A and B, respectively, and 0.27 and 0.20 for FD-7A and B, respectively. Higher ratios are predictive of lower cetane numbers; conversely lower ratios are predictive of higher cetane numbers. Ratios for FD-2 (A and B) and FD-7 (A and B) blends are very close and will likely be closer to targeted cetane numbers (Table 1), while FD-4A and -4B are considerably different, both with intermediate cetane values, but with FD-4A predicted to be closer to the targeted cetane numbers than FD-4B.

The absence of olefinic resonances in the ${ }^{1} \mathrm{H}$ NMR spectra is not surprising. Each FACE formulation is produced by blending refined petroleum streams to meet the target parameters. Olefins become saturated during hydrotreating and therefore no longer represent a significant fraction of the resulting fuel.

\section{$2.3{ }^{13} \mathrm{C}\left\{{ }^{1} \mathrm{H}\right\}$ NMR Data Comparison}

The quantitative ${ }^{13} \mathrm{C}\left\{{ }^{1} \mathrm{H}\right\}$ NMR results provide a picture consistent with the ${ }^{1} \mathrm{H}$ NMR results described above. ${ }^{13} \mathrm{C}\left\{{ }^{1} \mathrm{H}\right\}$ NMR complements and expands upon the information obtained from the ${ }^{1} \mathrm{H}$ NMR, in particular by further defining the aromatic and aliphatic carbons, providing a better discrimination of carbon structural types. However, this additional information does not diminish the value of the ${ }^{1} \mathrm{H}$ NMR data, which can be more rapidly obtained and allows rapid differentiation of fused ring aromatic systems, neither of which is a strength of ${ }^{13} \mathrm{C}\left\{{ }^{1} \mathrm{H}\right\}$ NMR.

As introduced above, Figure 1 allows a visual comparison of the integrated ${ }^{13} \mathrm{C}\left\{{ }^{1} \mathrm{H}\right\}$ NMR data using chemical shift regions identical to those previously reported (Alnajjar et al. 2010). Table 2 provides numerical values corresponding to the data in Figure 1.

The levels of carbonyl-containing compounds and olefinic compounds are extremely low, and the reported levels may not be significant.

Overall, the number of aromatic carbons is relatively consistent between the FACE A and B blend sets. As mentioned previously, FD-2A and -2B are effectively the same with the same number of substituted and protonated aromatic carbons. FD-4B and -7B have increased aromatic carbon numbers (sum of substituted aromatic and protonated aromatic carbons), by about $1.6 \%$ and $2.5 \%$, respectively, over FD-4A and -7A. The decreases in monoaromatic carbons and increases in substituted carbons are consistent with the ${ }^{1} \mathrm{H}$ NMR results mentioned above, indicating increased di- and tri-aromatics in the FD-4B and -7B blends, as well as the increased alkyl substitution of aromatic rings.

The ${ }^{13} \mathrm{C}\left\{{ }^{1} \mathrm{H}\right\}$ NMR results for cycloparaffinic methylenes (CP5) are effectively unchanged for both blend sets (FACE A and FACE B), providing one indication that the naphthenic component for each fuel is also similar. A more robust indicator of naphthenic carbon content could be derived by comparing the areas of the "naphthenic hump" (see discussion below) between the two blend sets. Unfortunately, these data are not presently available for the FACE A fuels, but from the FACE B fuels we can see a strong correlation between CP5 and percent naphthenic carbons, which should support the assertion of consistent naphthenic/cycloparaffinic compositions.

Comparing the ${ }^{13} \mathrm{C}\left\{{ }^{1} \mathrm{H}\right\}$ NMR results can also provide an indication of relative $n$-paraffin (straight chain paraffins) chain length, as well as iso-paraffin (branched paraffins) composition. The $n$-paraffin chain length is generally shorter for each of the FACE B blends. This is shown by consistently lower 
integration values for chain $\beta$-, $\gamma$-, and $\delta$-methylenes (CP6 and CP3, respectively), and lower or consistent values for the chain $\alpha$-methyl region, CP9. As shown in Figure 3, CP6 and CP3 represent paraffinic carbons that are 2-4 carbon units away from a terminal methyl group $\left(\mathrm{C}_{\alpha}\right)$, and $\mathrm{C}_{\delta}$ is more than about 6 methylene units away from another attached carbon group (i.e., branching carbons, aliphatic or aromatic rings, etc.). Changes in the iso-paraffin composition may be identified by examining the changes in the paraffinic methine regions (CP1 and CP2), and the branched chain methyl region (CP10). FD-2B and FD-4B have increased or constant values for each of these carbon types. The relative quantity of isoparaffins has likely increased in these two fuel blends, over FD-2A and FD-4A. Interestingly, the same indicators provide contradictory information for FD-7B, where integrations for CP1 and CP2 are reduced by approximately $25 \%$, and CP10 increases by a factor of 5 , leading to an ambiguous evaluation of isoparaffins for FD-7B.

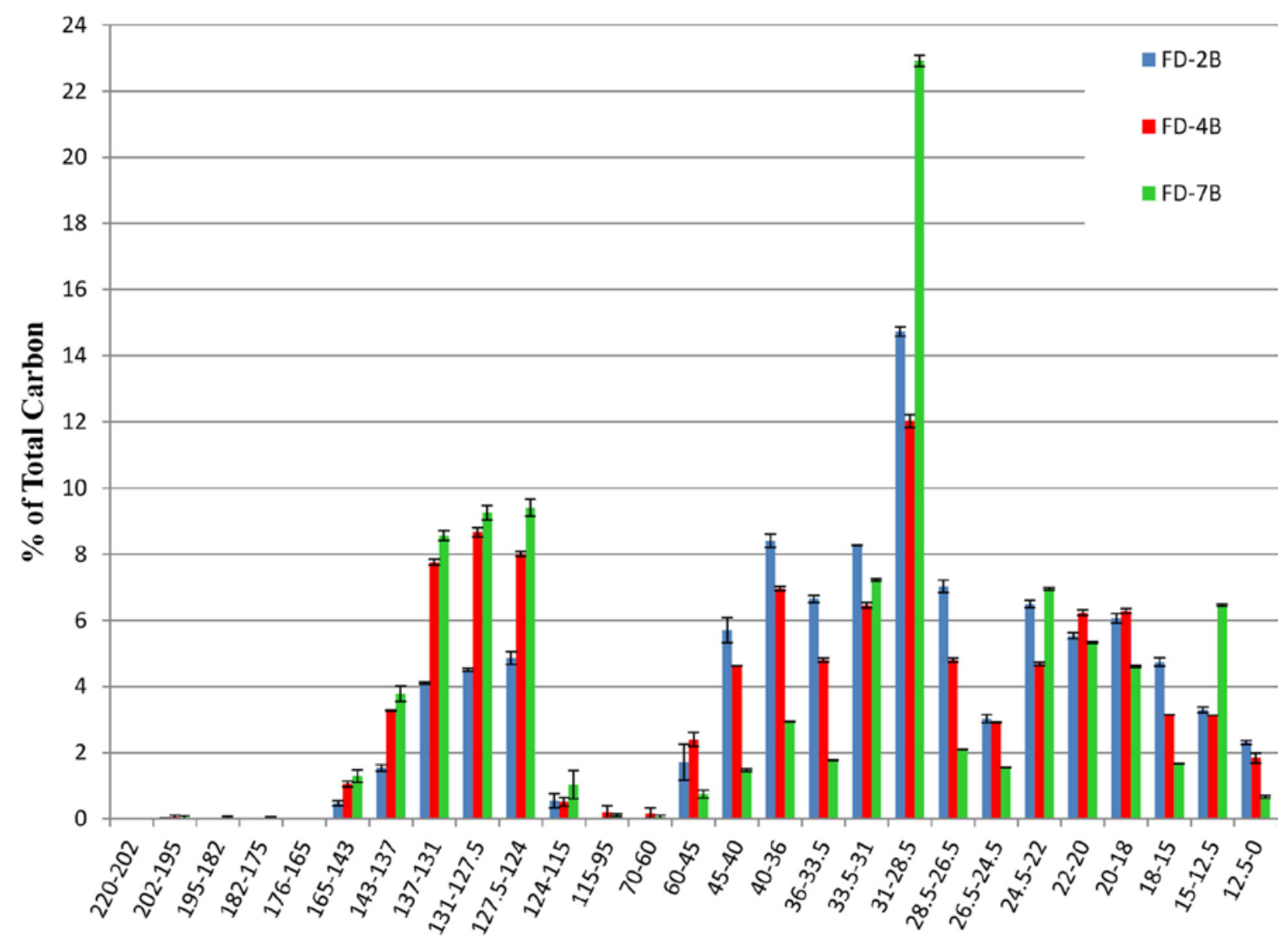

Carbon Types by Chemical Shift (ppm)

Figure 3. Normalized Carbon Type Distribution of Reblended FACE Diesel Fuels FD-2B, FD-4B, and FD-7B. Error bars represent one standard deviation above and below the average of three integrated values for each ${ }^{13} \mathrm{C}\left\{{ }^{1} \mathrm{H}\right\}$ NMR chemical shift region.

Apparent discrepancies in data interpretation should be examined in light of trending data. Ambiguities can sometimes be resolved by narrowing integration regions. The next section utilizes this approach to interpreting the ${ }^{13} \mathrm{C}\left\{{ }^{1} \mathrm{H}\right\}$ NMR data, and similar approaches may be taken in interpreting ${ }^{1} \mathrm{H}$ NMR spectral regions, as described above in the discussion pertaining to fused-ring aromatics. If 
narrower integration regions do not prove to be satisfactory, some of the more detailed spectral analysis techniques described below may resolve overlapping resonances, or simply be able to provide more information, such as hydrogen multiplicity or carbon connectivity.

\subsection{Detailed ${ }^{13} \mathrm{C}\left\{{ }^{1} \mathrm{H}\right\}$ NMR Interpretation}

Figure 3 and Table 6 use narrower chemical shift ranges, and a more detailed graphical breakdown in an effort to provide a more thorough analysis of the ${ }^{13} \mathrm{C}\left\{{ }^{1} \mathrm{H}\right\}$ NMR spectra of the version $\mathrm{B}$ fuels than was undertaken for the original version A fuels. Coupling this information with targeted integration of several diagnostic ${ }^{13} \mathrm{C}\left\{{ }^{1} \mathrm{H}\right\}$ NMR regions, additional information may be derived. Because this approach was not taken for FD-2A, -4A, and -7A, the results are not compared in this work. A summary table of chemical structure characteristics for FD-2B, $-4 \mathrm{~B}$, and $-7 \mathrm{~B}$ is presented in Table 7.

Also shown in Figure 3 and Table 6 are metrics showing the reproducibility of the NMR integrations. The integration of each chemical shift region can change slightly dependent upon the person performing the integration. Changes may arise from differences in phasing, differences in baseline correction, and differences in the ability to accurately discriminate a peak, particularly in regions with a low signal-tonoise ratio. These small variations are shown in Table 6 as standard deviations and in Figure 3 as error bars representing one standard deviation above and below the normalized average integration value.

The percent of aromatic carbons for each fuel sample is listed in Table 7 and overall is relatively close to the comparable fuel from the previous blend. Aromatic carbons may be found by adding the integrated values for CA2 and CA3; that is, for FD-2A, $-4 \mathrm{~A},-7 \mathrm{~A}$, the percent of aromatic carbons is $16.98,27.88$, and 30.65, respectively, and for FD-2B, $-4 \mathrm{~B},-7 \mathrm{~B}$, the percent of aromatic carbons is 16.06, 29.51, and 33.14, respectively. From Table 6, this is the same as adding the integrated values contained in the region from 165 to 95 ppm.

General regions in the ${ }^{13} \mathrm{C}\left\{{ }^{1} \mathrm{H}\right\}$ NMR were used to estimate the number and type of aliphatic and naphthenic protonated carbons; that is, $\mathrm{CH}, \mathrm{CH}_{2}$, and $\mathrm{CH}_{3}$. Estimates for naphthenic and paraffinic carbons were made by using the concept of a "naphthenic hump," presented by Altgelt and Boduszynski (1994). The area under the curve, estimated from the minima of groups of NMR resonances from about 15-60 ppm, was used to quantify naphthenic carbons. NMR resonances not bound by this curve were considered to represent paraffinic carbons and were determined by difference. Making this estimate introduces some error and may overestimate the value of naphthenic carbons at the expense of paraffinic carbons.

Long chain $n$-paraffinic carbons were attributed to resonances identified in Table 8 as $C_{\alpha}-C_{\varepsilon}$. Regions between these resonances were attributed to iso-paraffins. Both sets of values were obtained after accounting for the naphthenic carbons and, as mentioned above, may underestimate the value for each paraffinic region. Values presented in Table 8 were also used to calculate the average $n$-paraffin chain length. Because of the error introduced in identifying naphthenic and paraffinic contributions, the calculated value for chain length should be used cautiously, but magnitude and trend information should be valid. In this case, there is a decreasing $n$-paraffin chain length with increasing FACE number. Decreasing $n$-paraffin chain length should increase the sample volatility, which for FD-7 seems to be in accord with the desired low temperature value for $\mathrm{T}_{90}$ in Table 1. 
Table 6. Detailed Chemical Shift Regions for Normalized ${ }^{13} \mathrm{C}\left\{{ }^{1} \mathrm{H}\right\}$ Percent Composition of Reblended FACE Fuels

\begin{tabular}{|c|c|c|c|c|c|c|c|}
\hline \multirow[b]{2}{*}{$\begin{array}{l}\text { Chemical } \\
\text { Shift }\end{array}$} & \multirow[b]{2}{*}{ Structure Definition } & \multicolumn{2}{|c|}{ FD-2B } & \multicolumn{2}{|c|}{ FD-4B } & \multicolumn{2}{|c|}{ FD-7B } \\
\hline & & $\% \mathrm{C}$ & $\begin{array}{c}\text { Std } \\
\text { Deviation }\end{array}$ & $\% \mathrm{C}$ & $\begin{array}{c}\text { Std } \\
\text { Deviation }\end{array}$ & $\% \mathrm{C}$ & $\begin{array}{c}\text { Std } \\
\text { Deviation }\end{array}$ \\
\hline $220-202$ & Ketone Carbonyl & 0 & 0 & 0 & 0 & 0 & 0 \\
\hline 202-195 & Aldehyde Carbonyl & 0 & 0 & 0.1 & 0.06 & 0.0 & 0.05 \\
\hline $195-182$ & Quinone Carboxyl & 0 & 0 & 0 & 0 & 0.1 & 0.03 \\
\hline $182-176$ & Acid Carboxyl & 0 & 0 & 0 & 0 & 0 & 0.03 \\
\hline $176-165$ & Ester or Amide Carboxyl & 0 & 0 & 0 & 0 & 0 & 0 \\
\hline $165-143$ & Alkyl (other than methyl), or heteroatom (N, O, S) substituted aromatic & 0.5 & 0.07 & 1.1 & 0.09 & 1.3 & 0.19 \\
\hline 143-137 & Tertiary carbon in alkyl substituted aromatics & 1.5 & 0.09 & 3.3 & 0.01 & 3.8 & 0.24 \\
\hline $137-131$ & Tertiary carbon in naphthalene units and methyl substituted aromatics & 4.1 & 0.03 & 7.8 & 0.09 & 8.6 & 0.15 \\
\hline $131-127.5$ & $\begin{array}{l}\text { Protonated and internal aromatic carbon, substituted carbon in alkenes }\left(\mathrm{R}_{2} \mathrm{C}=\mathrm{CR}_{2}\right) \text {, orth and } \\
\text { meta } \mathrm{CH} \text { in toluene }\end{array}$ & 4.5 & 0.04 & 8.7 & 0.14 & 9.3 & 0.21 \\
\hline $127.5-124$ & $\begin{array}{l}\text { Protonated and internal aromatic carbon, substituted carbon in alkenes }\left(\mathrm{RHC}=\mathrm{CR}_{2}\right) \text {, para } \mathrm{CH} \text { in } \\
\text { toluene }\end{array}$ & 4.9 & 0.19 & 8.0 & 0.08 & 9.4 & 0.25 \\
\hline $124-115$ & Protonated aromatic carbon, substituted carbon in alkenes $\left(\mathrm{RHC}=\mathrm{CR}_{2}\right)$ & 0.5 & 0.22 & 0.5 & 0.13 & 1.0 & 0.43 \\
\hline $115-95$ & Unsubstituted carbon in alkenes $\left(\mathrm{CH}_{2}=\mathrm{CR}_{2}\right)$. Heteroatom substituted carbons & 0 & 0 & 0.2 & 0.20 & 0.1 & 0.05 \\
\hline $70-60$ & $\mathrm{CH}_{2}$ adjacent to oxygen and $\mathrm{C}$ in tertiary alchols & 0 & 0 & 0.2 & 0.16 & 0.1 & 0.06 \\
\hline $60-45$ & $\mathrm{CH}$ adjacent to tertiary and isopropyl groups. $\mathrm{CH}_{3}$ in ether linkage & 1.7 & 0.54 & 2.4 & 0.21 & 0.7 & 0.12 \\
\hline $45-40$ & $\mathrm{CH}$ in allylic and benzylic groups and in joining tetralin ring & 5.7 & 0.38 & 4.6 & 0.00 & 1.5 & 0.03 \\
\hline $40-36$ & $\mathrm{CH}_{2}$ adjacent to substituted double bonds and tertiary carbon & 8.4 & 0.20 & 7.0 & 0.07 & 2.9 & 0.01 \\
\hline 36-33.5 & $\mathrm{CH}, \mathrm{CH}_{2} \beta$ from secondary carbon and in cyclopentyl and cyclohexyl rings & 6.7 & 0.11 & 4.8 & 0.05 & 1.8 & 0.01 \\
\hline $33.5-31$ & $\mathrm{CH}, \mathrm{CH}_{2} \gamma$ from $\mathrm{CH}_{3} . \mathrm{CH}_{2} \alpha$ to allylic and beta to aromatic groups & 8.3 & 0.01 & 6.5 & 0.09 & 7.2 & 0.04 \\
\hline $31-28.5$ & $\mathrm{C}$ in open chains. $\mathrm{CH}_{2}$ benzylic and $\mathrm{CH}_{2}$ not adjacent to $\mathrm{CH}$ in alkyl group & 14.7 & 0.14 & 12.0 & 0.19 & 22.9 & 0.17 \\
\hline 28.5-26.5 & $\mathrm{CH}, \mathrm{CH}_{2}$ in open chains. $\mathrm{CH}_{2}$ in cyclohexyl groups and $\mathrm{CH}_{3}$ in tert-buty ether & 7.0 & 0.19 & 4.8 & 0.05 & 2.1 & 0.00 \\
\hline 26.5-24.5 & Some naphthenic $\mathrm{CH}_{2} \cdot \mathrm{CH}_{2} \beta$ in propyl, indan and cyclopentyl groups & 3.0 & 0.12 & 2.9 & 0.02 & 1.5 & 0.00 \\
\hline $24.5-22$ & $\mathrm{CH}_{2} \gamma$ from terminal $\mathrm{CH}_{3}$. $\mathrm{CH}_{2} \beta$ in unsubstituted tetralin & 6.5 & 0.11 & 4.7 & 0.05 & 7.0 & 0.04 \\
\hline $22-20$ & $\mathrm{CH}_{3} \alpha$ in hydroaromatics and alkyls not shielded by adjacent rings or groups & 5.5 & 0.09 & 6.2 & 0.08 & 5.3 & 0.03 \\
\hline $20-18$ & $\mathrm{CH}_{3} \alpha$ in hydroaromatics and alkyls shielded by adjacent rings or groups & 6.1 & 0.15 & 6.3 & 0.07 & 4.6 & 0.03 \\
\hline $18-15$ & $\mathrm{CH}_{3}$ in cyclohexanes and $\beta$ in ethyl aromatics and ethers & 4.7 & 0.13 & 3.1 & 0.01 & 1.7 & 0.01 \\
\hline $15-12.5$ & $\mathrm{CH}_{3} \gamma$ to an aromatic ring or shielded by two adjacent rings or groups, chain $\alpha-\mathrm{CH}_{3}$ & 3.3 & 0.08 & 3.1 & 0.00 & 6.5 & 0.04 \\
\hline $12.5-5$ & $\mathrm{CH}_{3} \gamma$ to aromatic rings or ethyl substituted cyclohexanes & 2.3 & 0.06 & 1.8 & 0.15 & 0.7 & 0.04 \\
\hline
\end{tabular}


Table 7. Summary of New FACE Diesel Chemical Structure Characteristics from ${ }^{13} \mathrm{C}\left\{{ }^{1} \mathrm{H}\right\}$ NMR Normalized by Percent Carbon Type

\begin{tabular}{|c|c|c|c|}
\hline & \multicolumn{3}{|c|}{$\% \mathrm{C}$} \\
\hline & FD-2B & FD-4B & FD-7B \\
\hline \multicolumn{4}{|l|}{ General Carbon Types } \\
\hline Aromatic Carbon & 16.0 & 29.5 & 33.4 \\
\hline Aliphatic Carbon & 84.0 & 70.5 & 66.4 \\
\hline CH Carbon & 7.4 & 7.0 & 2.2 \\
\hline $\mathrm{CH}_{2}$ Carbon & 54.6 & 42.6 & 45.4 \\
\hline $\mathrm{CH}_{3}$ Carbon & 21.9 & 20.6 & 18.7 \\
\hline \multicolumn{4}{|l|}{ Aromatic Carbon Breakdown } \\
\hline Total Aromatic Carbon & 16.0 & 29.5 & 33.3 \\
\hline Carbonyl Carbon & 0 & 0 & 0.2 \\
\hline Carboxyl Carbon & 0 & 0 & 0 \\
\hline Phenolic Carbon & 0 & 0 & 0 \\
\hline $\mathrm{CH}_{2} / \mathrm{CH}$ Substituted Aromatic Carbon & 1.8 & 3.2 & 4.6 \\
\hline Naphthene Substituted Aromatic Carbon & 1.8 & 3.2 & 3.9 \\
\hline $\mathrm{CH}_{3}$ Substituted Aromatic Carbon & 1.7 & 3.0 & 3.4 \\
\hline Internal (Bridgehead) Aromatic Carbon & 1.2 & 2.2 & 2.6 \\
\hline Peripheral Unsubstituted Aromatic Carbon & 9.4 & 16.6 & 18.6 \\
\hline Heteroaromatic Carbon & 0 & 1.2 & 0.2 \\
\hline \multicolumn{4}{|l|}{ Naphthenic Carbon Breakdown } \\
\hline Total Naphthenic Carbon & 39.5 & 28.0 & 11.2 \\
\hline Naphthenic CH & 6.4 & 5.6 & 2.0 \\
\hline Naphthenic $\mathrm{CH}_{2}$ & 28.5 & 19.6 & 8.1 \\
\hline Naphthenic $\mathrm{CH}_{3}$ & 4.6 & 2.7 & 1.1 \\
\hline \multicolumn{4}{|l|}{ Paraffinic Carbon Breakdown } \\
\hline Total Paraffinic Carbon & 43.5 & 42.6 & 55.2 \\
\hline$n$-Paraffin Character of Sample & 8.1 & 7.4 & 30.2 \\
\hline iso-Paraffin Character of Sample & 35.4 & 35.2 & 25.0 \\
\hline Average $n$-Paraffin Chain Length & 25 & 17 & 15 \\
\hline
\end{tabular}


Table 8. Normalized Integration of $n$-Paraffin Carbons from ${ }^{13} \mathrm{C}\left\{{ }^{1} \mathrm{H}\right\}$ NMR

\begin{tabular}{lcccc}
\hline \multirow{2}{*}{$\begin{array}{l}\text { Carbon } \\
\text { Types }\end{array}$} & $\begin{array}{c}\text { Chemical Shift } \\
\text { Region (ppm) }^{(\mathbf{a})}\end{array}$ & \multicolumn{3}{c}{ \%C } \\
\cline { 3 - 5 } & $31.95-31.85$ & 0.4 & 0.6 & 4.2 \\
\hline $\mathrm{C}_{\gamma}$ & $29.75-29.25$ & 6.1 & 4.8 & 18.2 \\
$\mathrm{C}_{\delta}+\mathrm{C}_{\varepsilon}$ & $22.7-22.6$ & 1.2 & 1.2 & 4.2 \\
$\mathrm{C}_{\beta}$ & $14.1-14.0$ & 0.4 & 0.7 & 3.6 \\
$\mathrm{C}_{\alpha}$ & 25 & 17 & 15 \\
Avg. n-Paraffin Chain Length & & FD-4B & FD-7B \\
\hline
\end{tabular}

(a) The chemical shift region is approximate and should be carefully identified for each spectrum.

\subsection{Comparison of ${ }^{1} \mathrm{H}$ and ${ }^{13} \mathrm{C}\left\{{ }^{1} \mathrm{H}\right\}$ NMR Results for FACE "B" Diesel Fuels}

The conclusions drawn from ${ }^{1} \mathrm{H}$ NMR and ${ }^{13} \mathrm{C}\left\{{ }^{1} \mathrm{H}\right\}$ NMR for a single fuel blend should be consistent. We found this to be the case or when there was a disagreement between the values obtained, then that disagreement could be resolved. A brief comparison is presented in Tables 9 and 10 .

Table 9. $\quad{ }^{1} \mathrm{H}$ and ${ }^{13} \mathrm{C}\left\{{ }^{1} \mathrm{H}\right\}$ NMR Comparison of Aromatic Characteristics, Results Normalized by Carbon Type

\begin{tabular}{lrrrrrr}
\hline & \multicolumn{6}{c}{ \% } \\
\cline { 2 - 7 } & \multicolumn{2}{c}{ FD-2B } & \multicolumn{2}{c}{ FD-4B } & \multicolumn{2}{c}{ FD-7B } \\
\hline Structure & \multicolumn{1}{c}{$\mathrm{H}$} & ${ }^{13} \mathrm{C}\left\{{ }^{1} \mathrm{H}\right\}$ & ${ }^{1} \mathrm{H}$ & ${ }^{13} \mathrm{C}\left\{{ }^{1} \mathrm{H}\right\}$ & \multicolumn{1}{c}{$\mathrm{H}$} & ${ }^{13} \mathrm{C}\left\{{ }^{1} \mathrm{H}\right\}$ \\
Protonated Aromatic (total) & 10.5 & 9.4 & 18.9 & 16.6 & 20.2 & 18.6 \\
Bridgehead Carbons & 0.9 & 1.2 & 2.5 & 2.2 & 2.8 & 2.6 \\
$\mathrm{CH}_{2}+\mathrm{CH}_{3}$ Substituted Aromatic Carbons & 7.1 & 5.4 & 16.5 & 9.5 & 17.0 & 11.9 \\
Aromatic Carbons with heteroatoms & & \multicolumn{1}{c}{0} & & 1.2 & & 0.2 \\
Total Aromatic Carbons & 18.5 & 16.0 & 37.9 & 29.5 & 40.0 & 33.3 \\
\hline
\end{tabular}

Table 10. ${ }^{1} \mathrm{H}$ and ${ }^{13} \mathrm{C}\left\{{ }^{1} \mathrm{H}\right\}$ NMR Comparison of Aliphatic Carbons, Results Normalized by Carbon Type

\begin{tabular}{lcccccc}
\hline & \multicolumn{6}{c}{ \% } \\
\cline { 2 - 7 } & \multicolumn{2}{c}{ FD-2B } & \multicolumn{2}{c}{ FD-4B } & \multicolumn{2}{c}{ FD-7B } \\
\hline Structure & ${ }^{1} \mathrm{H}$ & ${ }^{13} \mathrm{C}\left\{{ }^{1} \mathrm{H}\right\}$ & ${ }^{1} \mathrm{H}$ & ${ }^{13} \mathrm{C}\left\{{ }^{1} \mathrm{H}\right\}$ & ${ }^{1} \mathrm{H}$ & ${ }^{13} \mathrm{C}\left\{{ }^{1} \mathrm{H}\right\}$ \\
\hline Total Aliphatic Carbons & 82.3 & 84.0 & 64.7 & 70.5 & 62.9 & 66.4 \\
\hline
\end{tabular}


The values for protonated and bridgehead aromatic carbons are reasonably consistent between ${ }^{13} \mathrm{C}\left\{{ }^{1} \mathrm{H}\right\}$ NMR and ${ }^{1} \mathrm{H}$ NMR results, with the latter normalized to reflect the number of unique carbon environments. The bridgehead carbons from the ${ }^{1} \mathrm{H}$ NMR were derived by making assumptions that the di- and tri-aromatic compounds contributed 2 and 4 bridgehead carbons, respectively. While the normalized integration values deviate by about $0.5-1.5 \%$ between the two methods, this deviation is well within the expected tolerances.

Pronounced differences may be observed when comparing the values from ${ }^{1} \mathrm{H}$ and ${ }^{13} \mathrm{C}\left\{{ }^{1} \mathrm{H}\right\}$ NMR for methyl and methylene substituted aromatic carbons, and for differences in the total aromatic carbon values, but have origins which can be addressed. The ${ }^{1} \mathrm{H}$ NMR data presented in Tables 9 and 10 are normalized by carbon environment (from Table 4). Unfortunately, when using solely ${ }^{1} \mathrm{H}$ NMR data, normalization does not take into account carbon types that do not have attached protons, resulting in an overestimation of each of the presented carbon types, more significant for FD-4B and -7B than for 2B. Additionally, in the ${ }^{1} \mathrm{H}$ NMR, values for methyl and methylene carbons attached to an aromatic ring are obtained from a region of significant spectral overlap with paraffinic/naphthenic hydrogens, making the perceived values higher than the actual values. This may also be seen in a comparison of the integrated values for the aliphatic carbons, presented in Table 10. The values obtained from the ${ }^{13} \mathrm{C}\left\{{ }^{1} \mathrm{H}\right\}$ NMR may also suffer somewhat from overlap with adjacent integration regions, but because of the narrow resonances associated with the ${ }^{13} \mathrm{C}\left\{{ }^{1} \mathrm{H}\right\} \mathrm{NMR}$, the regions are more likely to be discrete, providing a more consistent representation of each carbon type. Finally, the ${ }^{1} \mathrm{H}$ NMR does not provide an analogous region for aromatic carbons attached to heteroatoms. Cumulative differences between results obtained from the ${ }^{1} \mathrm{H}$ and ${ }^{13} \mathrm{C}\left\{{ }^{1} \mathrm{H}\right\}$ ultimately account for the mismatch in total aromatic carbons shown in Table 9 . In the future, this mismatch may be accounted for by modifying the processing approach for the ${ }^{1} \mathrm{H}$ NMR spectra, and nearly eliminated by using information from the ${ }^{13} \mathrm{C}\left\{{ }^{1} \mathrm{H}\right\}$ NMR, specifically quantifying carbons without attached hydrogens and carbons with attached heteroatoms.

The data presented in the ${ }^{1} \mathrm{H}$ and ${ }^{13} \mathrm{C}\left\{{ }^{1} \mathrm{H}\right\}$ NMR spectra should be mutually supporting. With small adjustments in the interpretation of both sets of spectra, the results shown in Tables 9 and 10 demonstrate that these methods can lead to comparable results.

\subsection{Other Advanced Analysis Techniques}

Single-bond proton-carbon correlation (HSQC) NMR spectra have also been obtained for the three new FACE diesel fuels (FD-2B, -4B, and -7B). The aromatic region in particular can provide interesting information that can allow us to fingerprint fuels. Figure 4 shows the HSQC aromatic region for a series of FACE diesel fuels (FD-2B, -4B, and -7B), and two unrelated diesel fuels: one derived from shale oil and one derived from oil sands. The pattern evident in the FACE diesel fuels, (a)-(c), shows that they have one or more aromatic blend streams in common. Particularly obvious are the three distinct groupings, not present in either the oil shale or oil sands fuels, which are related to the mono-, di-, and triaromatic components of the FACE diesel fuels. When integrated, a quantitative assessment of these fuel components may be obtained. Taken as a whole, each of the fuels presents a different distribution of components, readily obvious in the HSQC data. The shale oil-derived fuel (d) shows monoaromatic components that are similar to the monoaromatic components found in the FACE diesel fuels. This is not the case for the oil sands-derived fuel, (e). These clearly observable differences allow us to readily 
discern different fuel blends or sources, and can later be correlated to physical properties derived from molecular structures within the fuels.

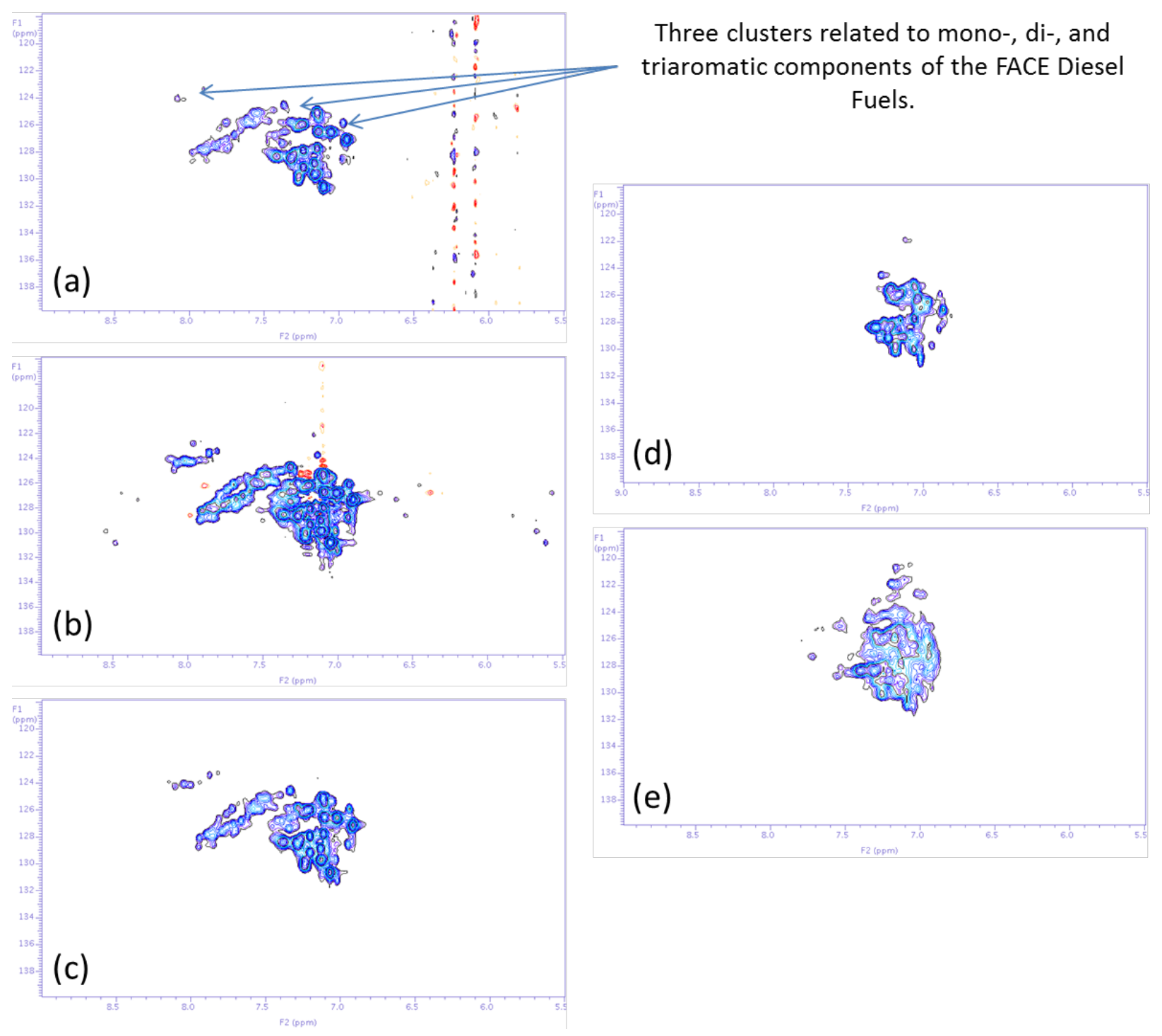

Figure 4. Single-bond, Proton-Carbon Correlation (HSQC) NMR Spectra of Fuels: (a) FACE 2B (FD-2B), (b) FACE 4B (FD-4B), (c) FACE 7B (FD-7B), (d) Shale oil-derived Diesel 1, and (e) Oil sands-derived diesel. The vertical axis is a subset of the ${ }^{13} \mathrm{C}\left\{{ }^{1} \mathrm{H}\right\}$ NMR spectrum, and the horizontal axis is a subset of the ${ }^{1} \mathrm{H}$ NMR spectrum. Both have units of parts-per-million chemical shift.

Additional NMR techniques are available that can provide further structural information for the fuel components. Useful NMR techniques might include homonuclear ${ }^{1} \mathrm{H}$ NMR experiments, such as correlation spectroscopy (COSY) and total correlation spectroscopy (TOCSY), which could differentiate between overlapping resonances in the aromatic-aliphatic methylene regions in the ${ }^{1} \mathrm{H} N M R$, or a homonuclear ${ }^{13} \mathrm{C}\left\{{ }^{1} \mathrm{H}\right\}$ experiment, like the "Incredible Natural-Abundance DoublE-QUAntum Transfer 
Experiment” (INADEQUATE) to determine carbon-carbon bond connectivity. Heteronuclear experiments such as single-bond proton-carbon correlation (HSQC) experiments have shown promise, so multiple-bond proton-carbon correlation (HMBC) experiments may also reveal some of the structural diversity of fuels from different sources. Additional information from these and other two-dimensional NMR techniques may be important in determining fuel structure-property relationships, and should be explored.

\subsection{Conclusion}

Based on ${ }^{1} \mathrm{H}$ and ${ }^{13} \mathrm{C}\left\{{ }^{1} \mathrm{H}\right\}$ NMR analyses, the new FACE diesel blends (FD-2B, -4B, and -7B) closely match the composition of the previous FACE diesel blends (FD-2A, -4A, and -7A). As noted above, the most significant differences arise in the aromatic region from the introduction of greater quantities of diand triaromatic compounds to the new FACE diesel blends, as well as greater alkyl-substitution of the aromatic rings. The aliphatic composition remains relatively consistent between the old and new fuels with minor differences that do not appear to substantially alter the character of the fuel. As mentioned previously, the percent-by-volume targets listed in Table 1 are not directly related to the percent of aromatic carbons, but from Table 7, the FACE B fuels have roughly achieved the desired aromatic ratios.

${ }^{1} \mathrm{H}$ and ${ }^{13} \mathrm{C}\left\{{ }^{1} \mathrm{H}\right\}$ NMR have also been shown to be useful in identifying key structural features in complex fuel mixtures. These techniques can be either mutually supporting or provide orthogonal information, leading to a better overall analysis than utilizing either approach in isolation. For example, as mutually supporting techniques, both provide data regarding alkyl substituents bound to aromatic rings, cyclic paraffins (naphthenes), and protonated or alkyl substituted aromatic carbons. Orthogonal information arises from the knowledge of fused aromatic rings from ${ }^{1} \mathrm{H}$ NMR, coupled with bridgehead carbons from ${ }^{13} \mathrm{C}\left\{{ }^{1} \mathrm{H}\right\}$ NMR, allows a more thorough assessment of aromatic and polyaromatic ring systems. Both ${ }^{1} \mathrm{H}$ and ${ }^{13} \mathrm{C}\left\{{ }^{1} \mathrm{H}\right\}$ NMR have been shown to provide a more comprehensive analysis of fuel mixtures when used together.

While the ${ }^{1} \mathrm{H}$ and ${ }^{13} \mathrm{C}\left\{{ }^{1} \mathrm{H}\right\}$ NMR spectra are both representative of each sample, differences in interpretation can arise primarily from overlapping resonances in the ${ }^{1} \mathrm{H}$ NMR. Overlapping chemical shift regions are less likely to be problematic in the ${ }^{13} \mathrm{C}\left\{{ }^{1} \mathrm{H}\right\}$ NMR spectra because there is greater dispersion of chemically inequivalent carbon environments. Additional considerations when deciding to use either ${ }^{1} \mathrm{H}$ or ${ }^{13} \mathrm{C}\left\{{ }^{1} \mathrm{H}\right\}$ NMR analysis will be time and effort. ${ }^{1} \mathrm{H}$ NMR spectra are considerably faster to obtain than ${ }^{13} \mathrm{C}\left\{{ }^{1} \mathrm{H}\right\}$ NMR spectra. While sufficient information may be obtained to answer many basic questions, standing alone, that information is neither as precise or accurate as can be obtained from $\mathrm{a}^{13} \mathrm{C}\left\{{ }^{1} \mathrm{H}\right\}$ NMR spectrum because of the differences in spectral dispersion between the two techniques, (i.e., about 0-12 ppm for ${ }^{1} \mathrm{H}$ NMR and 0-220 ppm for ${ }^{13} \mathrm{C}\left\{{ }^{1} \mathrm{H}\right\} \mathrm{NMR}$ ). 


\subsection{Methods}

All quantitative ${ }^{1} \mathrm{H}$ NMR and ${ }^{13} \mathrm{C}\left\{{ }^{1} \mathrm{H}\right\}$ NMR spectra were acquired at 499.67 and $125.65 \mathrm{MHz}$, respectively, on a Varian Inova System. All spectra were recorded at $25.0^{\circ} \mathrm{C}$ in 5 -mm outer diameter NMR tubes, spinning at $20 \mathrm{~Hz}$. Spectra were processed using analysis tools from Varian VNMRJ Version 2.2 Revision D software, or MestReNova Version 6.0.4-5850 software.

Quantitative ${ }^{13} \mathrm{C}\left\{{ }^{1} \mathrm{H}\right\}$ spectra were acquired using a $45^{\circ}$ observe pulse; acquisition and relaxation delay times of 3 and 5 seconds, respectively, with ${ }^{1} \mathrm{H}$ Waltz decoupling during the acquisition delay period for nuclear Overhauser enhancement (NOE) suppression; and $0.05 \mathrm{M} \mathrm{Cr}(\mathrm{acac})_{3}$ for $\mathrm{T}_{1}$ reduction and quenching of any residual NOE, where acac is $\mathrm{CH}_{3} \mathrm{C}(\mathrm{O}) \mathrm{CHC}(\mathrm{O}) \mathrm{CH}_{3}$. These conditions lead to an average integral uncertainty of about $\pm 2 \%$ (in carbon aromaticity). Carbon-13 spectra are referenced to internal $\mathrm{CDCl}_{3}(77.16 \mathrm{ppm})$ (Gottlieb et al. 1997), tetramethylsilane (0 ppm), or the $\alpha$-carbon of linear long chain saturated hydrocarbons (14.16 ppm). Samples consisted of $0.20 \mathrm{~mL}$ of fuel diluted to $1.00 \mathrm{~mL}$ in $\mathrm{CDCl}_{3}$ with $0.05 \mathrm{M} \mathrm{Cr}(\mathrm{acac})_{3}$. Spectra resulted from 1,500-6,000 scans. Line broadening of $2.5 \mathrm{~Hz}$ was used for processing spectra to improve the signal-to-noise ratio. Quantitative results were obtained by integrating each sample spectrum on two or three separate occasions to account for variation in phasing and baseline correction approaches. Results are presented as normalized averages of the integrated area for each spectral region, and in the case of Table 6, the standard deviation is also reported.

Quantitative ${ }^{1} \mathrm{H}$ spectra were acquired using a $30^{\circ}$ observe pulse, with acquisition and relaxation delays of 3 and 8 seconds, respectively, for an 11-second recycle time. Samples consisted of about $50 \mathrm{mg}$ of fuel diluted to $1.00 \mathrm{~mL}$ in $\mathrm{CDCl}_{3}$. Addition of $\mathrm{Cr}(\mathrm{acac})_{3}$ did not change the integration values for the proton NMR. Measured proton ratios are relatively insensitive to conditions as long as recycle times are kept above about 5 seconds. Chemical shifts are referenced to internal tetramethylsilane (0 ppm) or to internal residual $\mathrm{CHCl}_{3}$ in solvent $\mathrm{CDCl}_{3}(7.26 \mathrm{ppm}$ ) (Gottlieb et al. 1997). Spectra resulted from 128 scans. Line broadening was not used. Quantitative results were obtained from single integrations of each spectrum, because unlike the ${ }^{13} \mathrm{C}\left\{{ }^{1} \mathrm{H}\right\}$ analyses, ${ }^{1} \mathrm{H}$ seemed to be less susceptible to phasing and baseline correction variations.

${ }^{1} \mathrm{H}-{ }^{13} \mathrm{C}$ single-bond proton-carbon correlation (HSQC) spectra were recorded on a $500 \mathrm{MHz}$ Varian Inova spectrometer equipped with a Noralac dual broadband probe. The standard Agilent HSQCAD pulse sequence was used with the standard coupling constant of $146 \mathrm{~Hz}$. Spectral editing was employed to distinguish methine/methyl groups as positive resonances and methylene groups as negative resonances. Acquisition parameters included 32 scans per increment with 400 increments with a spectral width of $5 \mathrm{kHz}$ in the F2 $\left({ }^{1} \mathrm{H}\right)$ dimension and $25 \mathrm{kHz}$ in the F1 $\left({ }^{13} \mathrm{C}\right)$ dimension. The data were then processed using zero filling to $2048 \times 2048$ complex data points and a Gaussian window function.

Spectral range assignment and interpretation of NMR results are based on ranges and methods presented by Altgelt and Boduszynski (1994). 


\subsection{References}

Algelt KH and MM Boduszynski. 1994. Composition and Analysis of Heavy Petroleum Fractions. Marcel Dekker, New York. Vol. 54 of Chemical Industries.

Alnajjar M, B Cannella, H Dettman, C Fairbridge, J Franz, T Gallant, R Gieleciak, D Hager, C Lay, S Lewis, M Ratcliff, S Sluder, J Storey, H Yin and B Zigler. 2010. Chemical and Physical Properties of the Fuels for Advanced Combustion Engines (FACE) Research Diesel Fuels. CRC Report No. FACE-1, Coordinating Research Council, Alpharetta, Georgia.

Gottlieb HE, V Kotlyar and A Nudelman. 1997. "NMR Chemical Shifts of Common Laboratory Solvents as Trace Impurities." Journal of Organic Chemistry 62(21):7512-7515. 



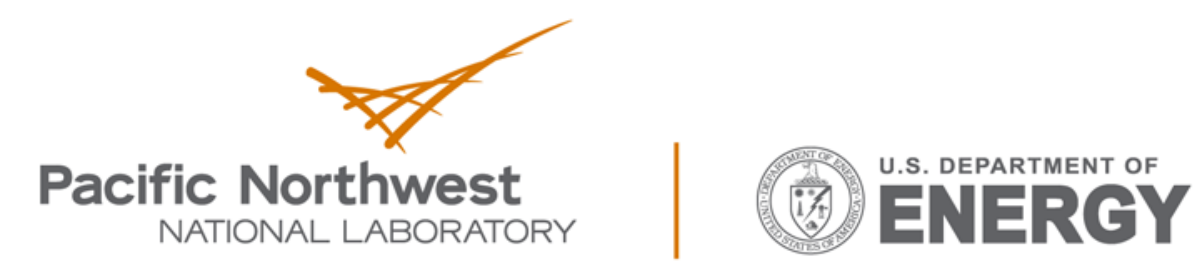

Proudly Operated by Battelle Since 1965

902 Battelle Boulevard

P.O. Box 999

Richland, WA 99352

1-888-375-PNNL (7665)

www.pnnl.gov 